\title{
ERRATUM
}

K. S. Bernard • P. W. Froneman

\section{Trophodynamics of selected mesozooplankton in the west-Indian sector of the Polar Frontal Zone, Southern Ocean}

Received: 1 August 2005/Published online: 7 October 2005

(C) Springer-Verlag 2005

\section{Polar Biology (2005) 28:594-606}

Unfortunately, in the published version of the article, the figures and the respective legends did not corre- spond. All figures with their correct legends are shown here.

The online version of the original article can be found at http:// dx.doi.org/10.007/s00300-005-0728-3

K. S. Bernard $(\bowtie) \cdot$ P. W. Froneman

Southern Ocean Group, Department of Zoology \& Entomology,

Rhodes University, P.O. Box 94, Grahamstown, South Africa

E-mail: g97b3042@campus.ru.ac.za 


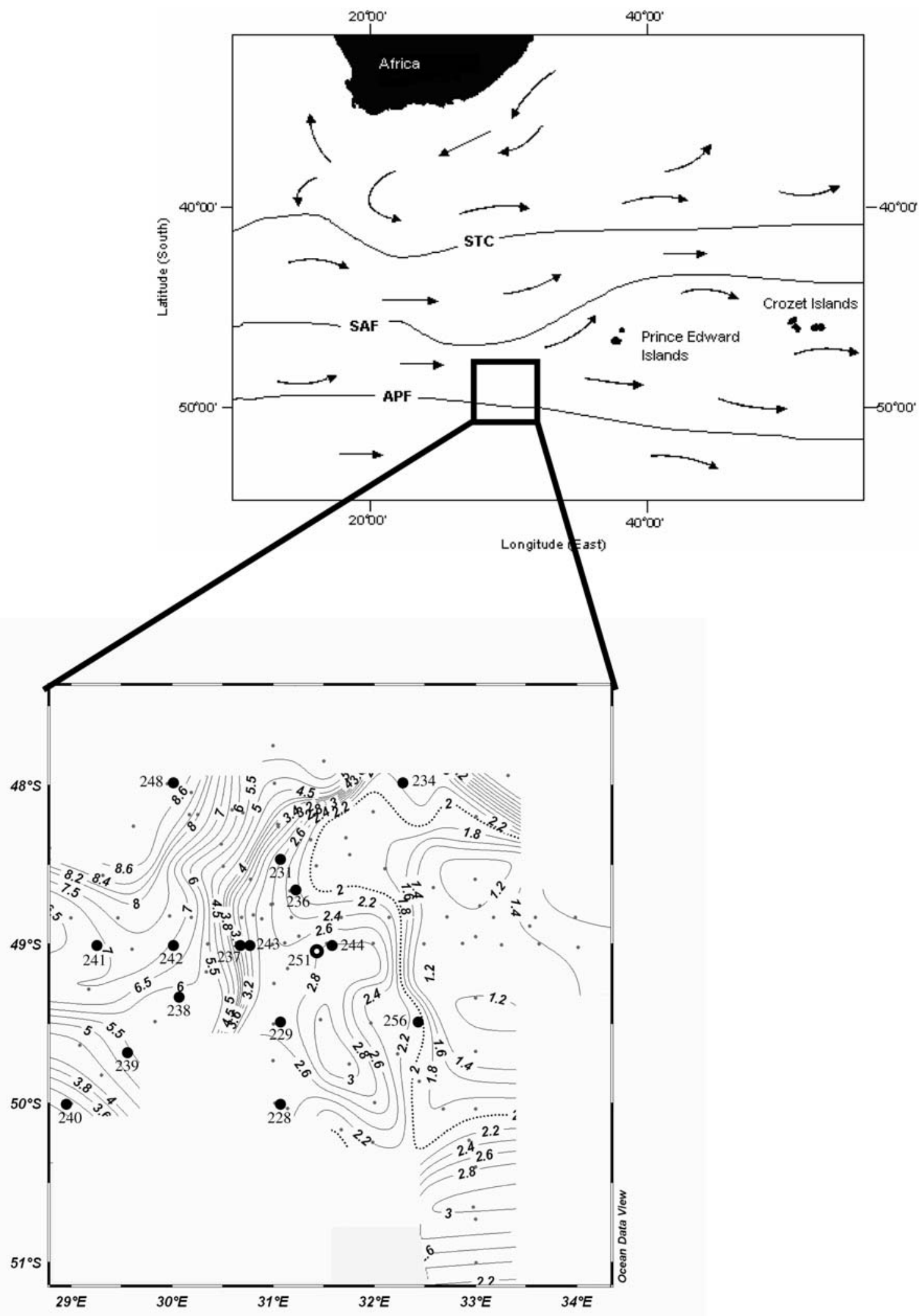

Fig. 1 Indian Ocean sector of the Southern Ocean, showing general positions of the major fronts: sub-Tropical convergence (STC), sub-Antarctic front (SAF) and Antarctic polar front (APF). The boxed-in region shows sub-surface $(200 \mathrm{~m})$ temperature isotherms in the area of investigation, the polar frontal zone (PFZ), austral autumn 2004. The frontal feature can be observed where the temperatures exhibit steep meridional gradients (i.e. where the contours are closest together). Black circles indicate the grazing stations occupied during the survey (numbered 228 to 256). The clear circle indicates the position of the $24 \mathrm{~h}$ grazing station, and is labelled 251 
Fig. 2 Mesozooplankton abundances (ind. $\mathrm{m}^{-2}$ ) at grazing stations in the subAntarctic zone group (SAZG) and the Antarctic zone group (AAZG), austral autumn 2004

Fig. 3 Percentage contribution of copepoda (represented by Calanus simillimus,

Clausocalanus spp.

Ctenocalanus spp. and Oithona similis) and pteropoda

(Limacina retroversa) to total mesozooplankton abundance at grazing stations in the SAZG and AAZG, austral autumn 2004

Fig. 4 Mesozooplankton biomass values (mg Dwt $\mathrm{m}^{-2}$ ) at grazing stations in the SAZG and the AAZG, austral autumn 2004
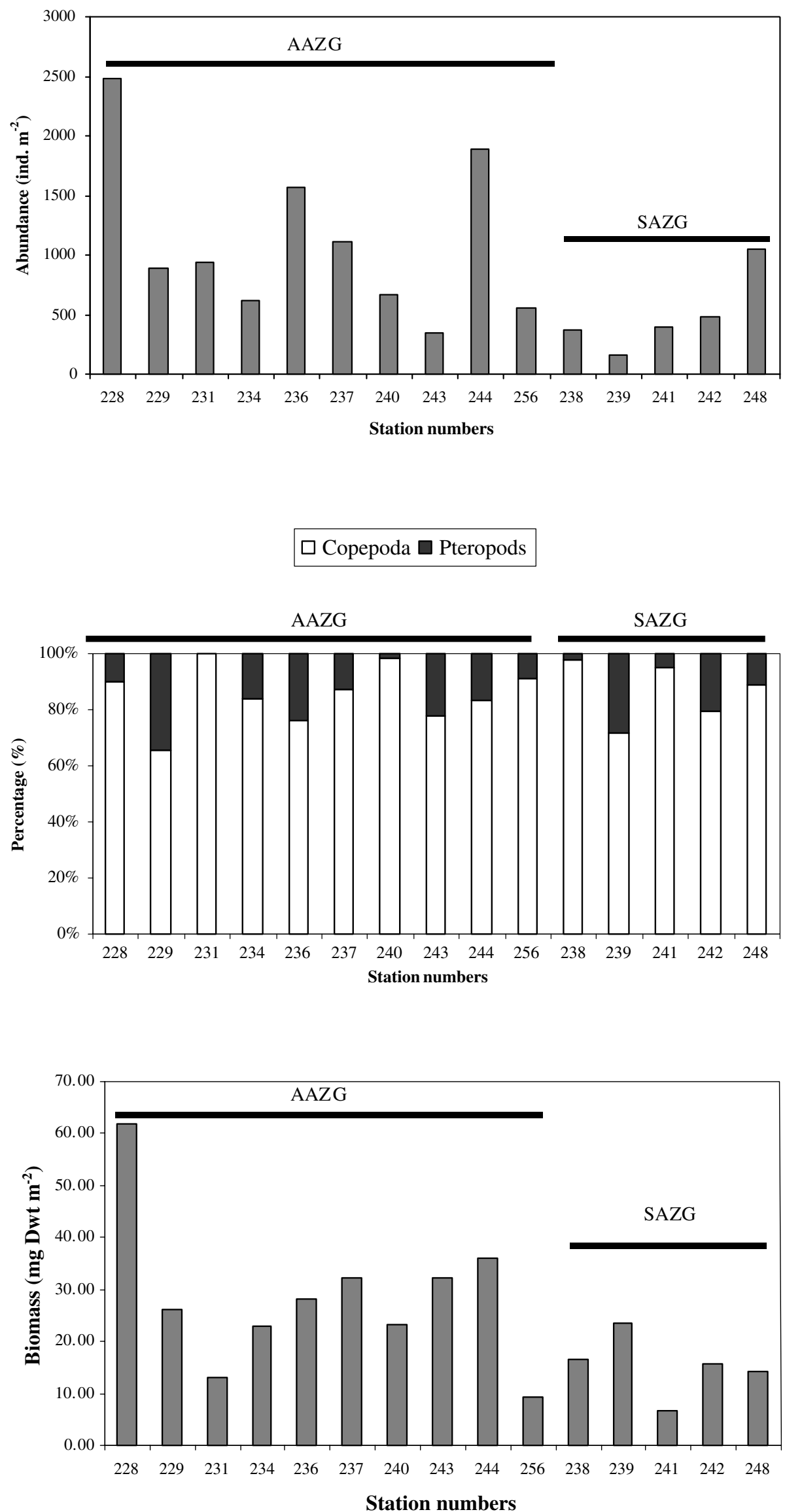
Fig. 5 Results of the cluster analysis of mesozooplankton community structure in the PFZ, austral autumn 2004

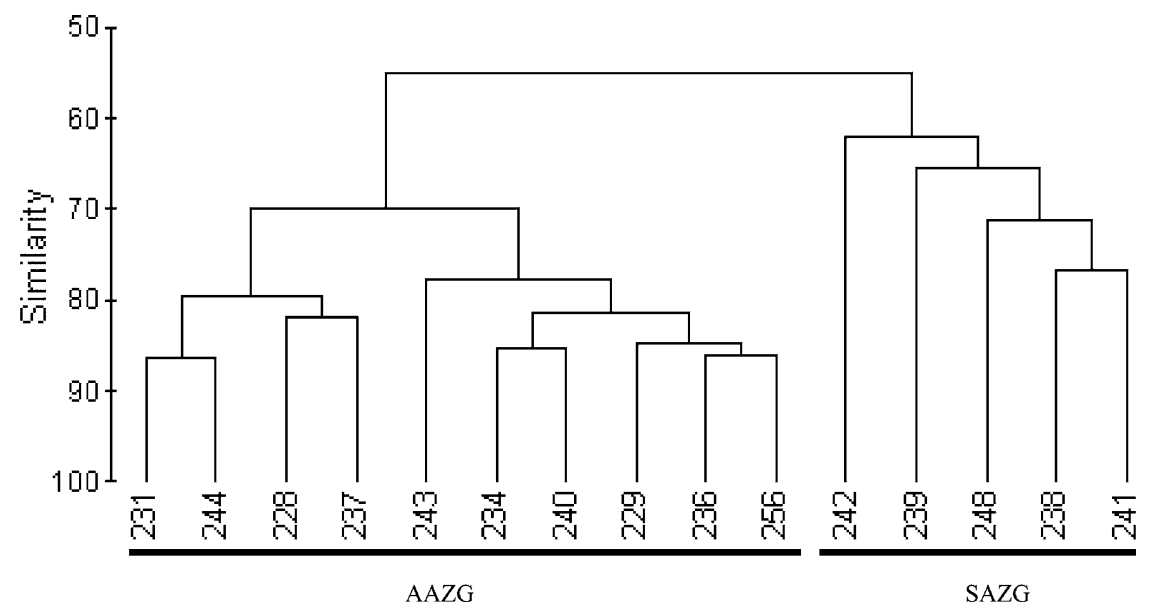

Fig. 6 Diel variation in gut pigment content for selected mesozooplankton species, PFZ, austral autumn 2004.

Thickened lines on the $x$-axis indicate periods of darkness
Limacina retroversa
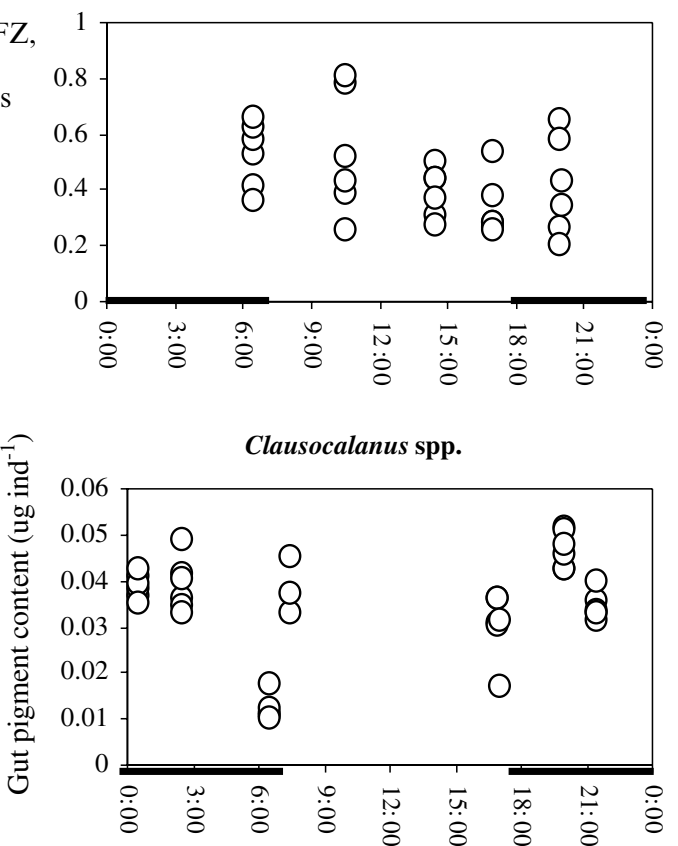

Oithona similis

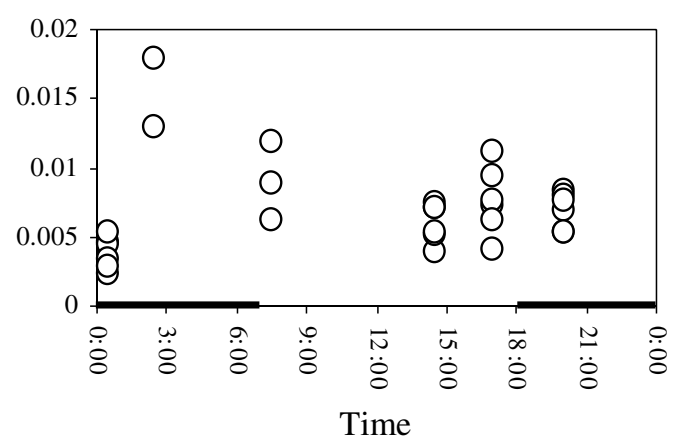

Calanus simillimus

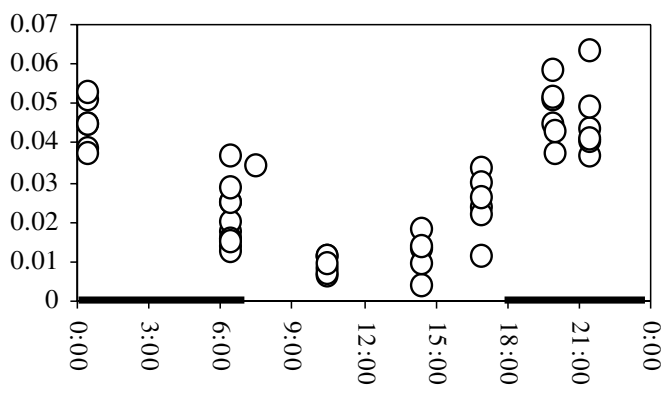

Ctenocalanus spp.

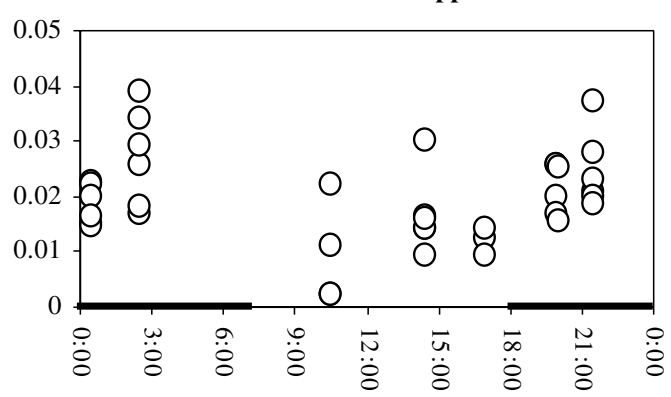


Fig. 7 Relative contribution of copepoda and pteropoda to total daily phytoplankton ingestion at grazing stations occupied in the SAZG and the AAZG, austral autumn 2004

\section{$\square$ Copepoda $\square$ Pteropoda}

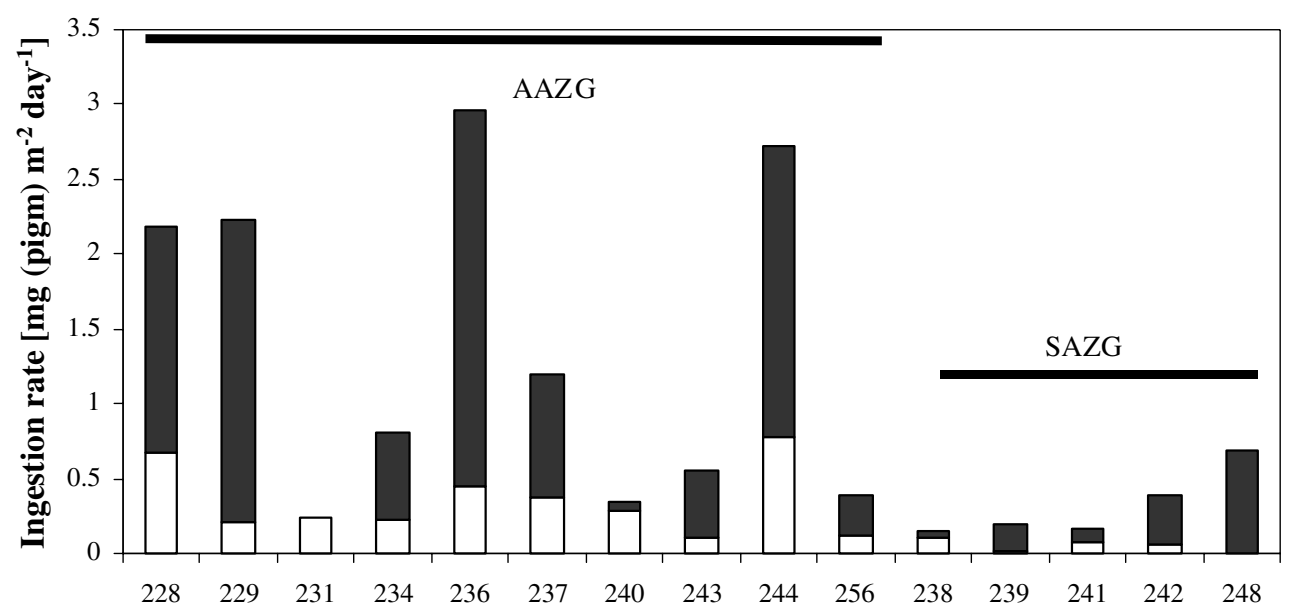

Station number 